\title{
Conservation status of the world's skinks (Scincidae): Taxonomic and geographic patterns in extinction risk
}

David G. Chapple ${ }^{\mathrm{a}, *}$, Uri Roll ${ }^{\mathrm{b}}$, Monika Böhm ${ }^{\mathrm{c}}$, Rocío Aguilar ${ }^{\mathrm{a}, \mathrm{d}}$, Andrew P. Amey ${ }^{\mathrm{e}}$, Chris C. Austin $^{f}$, Marleen Baling ${ }^{g}$, Anthony J. Barley ${ }^{h}$, Michael F. Bates ${ }^{i, j}$, Aaron M. Bauer ${ }^{k}$, Daniel G. Blackburn ${ }^{1}$, Phil Bowles ${ }^{\mathrm{m}}$, Rafe M. Brown ${ }^{\mathrm{n}}$, S.R. Chandramouli ${ }^{\mathrm{o}}$, Laurent Chirio ${ }^{\mathrm{p}}$, Hal Cogger ${ }^{q}$, Guarino R. Colli ${ }^{r}$, Werner Conradie ${ }^{s}$, Patrick J. Couper ${ }^{\mathrm{e}}$, Mark A. Cowan ${ }^{\mathrm{t}}$, Michael D. Craig ${ }^{\mathrm{u}, \mathrm{v}}$, Indraneil Das ${ }^{\mathrm{w}}$, Aniruddha Datta-Roy ${ }^{\mathrm{x}}$, Chris R. Dickman ${ }^{\mathrm{y}}$, Ryan J. Ellis $^{\mathrm{z} \text {,aa }}$, Aaron L. Fenner ${ }^{\mathrm{ab}}$, Stewart Ford ${ }^{\mathrm{ac}}$, S.R. Ganesh ${ }^{\mathrm{ad}}$, Michael G. Gardner ${ }^{\mathrm{ab}, \mathrm{ae}}$, Peter Geissler $^{\text {af }}$, Graeme R. Gillespie ${ }^{\text {ag }}$, Frank Glaw ${ }^{\text {ah }}$, Matthew J. Greenlees ${ }^{\text {ai }}$, Oliver W. Griffith $^{\text {ai }}$, L. Lee Grismer ${ }^{\text {aj }}$, Margaret L. Haines ${ }^{\text {ak }}$, D. James Harris ${ }^{\text {al }}$, S. Blair Hedges ${ }^{\text {am }}$, Rod A. Hitchmough ${ }^{\text {an }}$, Conrad J. Hoskin ${ }^{\text {ao }}$, Mark N. Hutchinson ${ }^{\text {ae }}$, Ivan Ineich $^{\mathrm{ap}}$, Jordi Janssen ${ }^{\mathrm{aq}}$, Gregory R. Johnston ${ }^{\text {ab, ae }}$, Benjamin R. Karin ${ }^{\mathrm{ar}}$, J. Scott Keogh ${ }^{\text {as }}$, Fred Kraus ${ }^{\text {at, }}$, Matthew LeBreton ${ }^{\text {au }}$, Petros Lymberakis ${ }^{\text {av }}$, Rafaqat Masroor ${ }^{\text {aw }}$, Peter J. McDonald ${ }^{\text {ax }}$, Sven Mecke ${ }^{\text {ay }}$, Jane Melville ${ }^{\text {ak }}$, Sabine Melzer ${ }^{\text {az }}$, Damian R. Michael ${ }^{\text {ba }}$, Aurélien Miralles $^{\text {ap }}$, Nicola J. Mitchell ${ }^{\mathrm{u}}$, Nicola J. Nelson ${ }^{\mathrm{bb}}$, Truong Q. Nguyen ${ }^{\mathrm{bc}}$, Cristiano de Campos Nogueira ${ }^{\text {bd }}$, Hidetoshi Ota ${ }^{\text {be }}$, Panayiotis Pafilis ${ }^{\text {bf }}$, Olivier S.G. Pauwels ${ }^{\text {bg }}$, Ana Perera $^{\text {al }}$, Daniel Pincheira-Donoso ${ }^{\text {bh }}$, Robert N. Reed ${ }^{\text {bi }}$, Marco A. Ribeiro-Júnior ${ }^{\text {bj }}$,

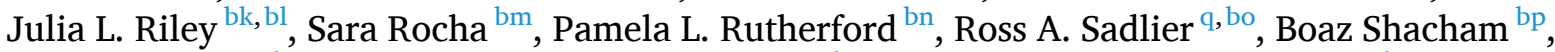
Glenn M. Shea ${ }^{\text {q, bq }}$, Richard Shine ${ }^{\text {ai }}$, Alex Slavenko ${ }^{\text {br }}$, Adam Stow ${ }^{\text {ai }}$, Joanna Sumner ${ }^{\text {ak }}$, Oliver J. S. Tallowin ${ }^{\text {bs }}$, Roy Teale ${ }^{\text {ac }}$, Omar Torres-Carvajal ${ }^{\text {bt }}$, Jean-Francois Trape ${ }^{\text {bu }}$, Peter Uetz ${ }^{\text {bv }}$,

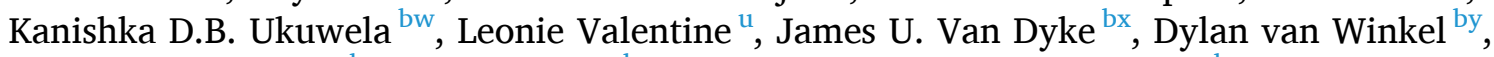
Raquel Vasconcelos ${ }^{\mathrm{al}}$, Miguel Vences ${ }^{\mathrm{bz}}$, Philipp Wagner ${ }^{\mathrm{ca}}$, Erik Wapstra ${ }^{\mathrm{cb}}$, Geoffrey M. While ${ }^{\mathrm{cb}}$, Martin J. Whiting ${ }^{\text {ai }}$, Camilla M. Whittington ${ }^{\mathrm{cc}}$, Steve Wilson ${ }^{\mathrm{e}}$, Thomas Ziegler $^{\mathrm{cd}, \mathrm{ce}}$, Reid Tingley ${ }^{\mathrm{a}, 1}$, Shai Meiri ${ }^{\mathrm{bk}, 1}$

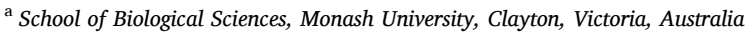

${ }^{\mathrm{b}}$ Mitrani Department of Desert Ecology, The Jacob Blaustein Institutes for Desert Research, Ben Gurion University, Midreshet Ben Gurion, Israel

${ }^{\mathrm{c}}$ Institute of Zoology, Zoological Society of London, Regent's Park, London NW1 4RY, United Kingdom

${ }^{\mathrm{d}}$ School of BioSciences, The University of Melbourne, Melbourne, Victoria, Australia

e Biodiversity and Geosciences Program, Queensland Museum, South Brisbane, Queensland, Australia

${ }^{\mathrm{f}}$ Museum of Natural Science and Department of Biological Sciences, Louisiana State University, Baton Rouge, LA 70803, USA

${ }^{g}$ Unitec Institute of Technology, Auckland 1142, New Zealand

${ }^{\mathrm{h}}$ School of Life Sciences, University of Hawaii, Honolulu, HI 96822, USA

${ }^{i}$ Department of Herpetology, National Museum, Bloemfontein 9300, South Africa

${ }^{\mathrm{j}}$ Department of Zoology \& Entomology, University of the Free State, Bloemfontein 9300, South Africa

${ }^{\mathrm{k}}$ Department of Biology and Center for Biodiversity and Ecosystem Stewardship, Villanova University, Villanova, PA, USA

${ }^{1}$ Department of Biology, Trinity College, Hartford, CT 06106, USA

m Biodiversity Assessment Unit, International Union for Conservation of Nature and Conservation International, Washington, DC, USA

${ }^{\mathrm{n}}$ Biodiversity Institute, University of Kansas, Lawrence, KS 66045, USA

${ }^{\circ}$ Department of Ecology and Environmental Sciences, School of Life Sciences, Pondicherry University, Puducherry, India

${ }^{\mathrm{p}}$ Lycée Saint-Exupéry, B.P. 31 Brazzaville, Congo

${ }^{q}$ Australian Museum Research Institute, Australian Museum, Sydney, NSW 2010, Australia

${ }^{\mathrm{r}}$ Departamento de Zoologia, Universidade de Brasília, Brasília, DF 70910-900, Brazil

\footnotetext{
* Corresponding author.
} 
${ }^{\mathrm{s}}$ Port Elizabeth Museum (Bayworld), Port Elizabeth 6013, South Africa

${ }^{\mathrm{t}}$ Western Australian Department of Biodiversity, Conservation and Attractions, Western Australia, Australia

" School of Biological Sciences, University of Western Australia, Nedlands, Western Australia 6009, Australia

${ }^{v}$ School of Environmental and Conservation Sciences, Murdoch University, Murdoch, Western Australia 6150, Australia

${ }^{\mathrm{w}}$ Institute of Biodiversity and Environmental Conservation, Universiti Malaysia Sarawak, 94300 Kota Samarahan, Sarawak, Malaysia

${ }^{\mathrm{x}}$ School of Biological Sciences, National Institute of Science Education \& Research, Bhubaneswar, Odisha 752050, India

${ }^{y}$ Desert Ecology Research Group, School of Life and Environmental Sciences, University of Sydney, NSW 2006, Australia

${ }^{\mathrm{z}}$ Biologic Environmental Survey, East Perth, Western Australia, Australia

${ }^{\text {aa }}$ Western Australian Museum, Welshpool, Western Australia, Australia

${ }^{\mathrm{ab}}$ College of Science and Engineering, Flinders University, Adelaide, Australia

${ }^{\text {ac }}$ Biota Environmental Sciences, Leederville, Western Australia, Australia

${ }^{\text {ad }}$ Chennai Snake Park, Rajbhavan post, Chennai 600 022, Tamil Nadu, India

${ }^{\text {ae }}$ South Australian Museum, North Tce Adelaide, South Australia 5001, Australia

${ }^{\text {af }}$ Museum Natur und Mensch, Freiburg, Germany

${ }^{\text {ag }}$ Flora and Fauna Division, Department of Environment and Natural Resources, Palmerston, Northern Territory, Australia

${ }^{\text {ah }}$ Zoologische Staatssammlung München (ZSM-SNSB), Münchhausenstr. 21, 81247 München, Germany

ai Department of Biological Sciences, Macquarie University, New South Wales 2109, Australia

${ }^{\text {aj }}$ Herpetology Laboratories, Department of Biology, La Sierra University, Riverside, CA 92515, USA

${ }^{\text {ak }}$ Department of Sciences, Museums Victoria, Melbourne, Australia

${ }^{\text {al }}$ CIBIO Research Centre in Biodiversity and Genetic Resources, InBIO, Universidade do Porto, Campus de Vairão, Rua Padre Armando Quintas, 4485 -661 Vairão, Vila do Conde, Portugal

am Center for Biodiversity, Temple University, Philadelphia, PA 19122, USA

${ }^{a}$ Department of Conservation, Wellington 6143, New Zealand

ao College of Science \& Engineering, James Cook University, Townsville, Queensland 4811, Australia

ap Institut de Systématique, Évolution, Biodiversité (ISYEB), Muséum national d'Histoire naturelle, CNRS, Sorbonne Université, EPHE, Université des Antilles 57 rue Cuvier, CP 50, 75005 Paris, France

${ }^{\text {aq }}$ Monitor Conservation Research Society, PO BOX 200, Big Lake Ranch, BC VOL 1GO, Canada

${ }^{\text {ar }}$ Museum of Vertebrate Zoology and Department of Integrative Biology, University of California, Berkeley, USA

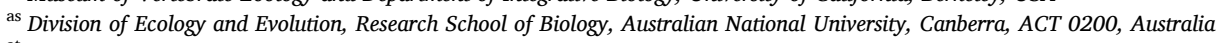

at Department of Ecology and Evolutionary Biology, University of Michigan, Ann Arbor, MI, USA

au Mosaic, BP 35353 Yaounde, Cameroon

${ }^{\text {av }}$ Vertebrates Department, National History Museum of Crete - University of Crete, Greece

${ }^{\text {aw }}$ Zoological Sciences Division, Pakistan Museum of Natural History, Islamabad 44000, Pakistan

${ }^{\text {ax }}$ Flora and Fauna Division, Northern Territory Department of Environment and Natural Resources, Alice Springs, Northern Territory 0871, Australia

ay Naturkundemuseum Paderborn, Im Schloßpark 9, 33104 Paderborn, Germany

${ }^{\mathrm{az}}$ Natural Environment Design, Auckland Council, Auckland, New Zealand

ba Institute for Land, Water and Society, Charles Sturt University, Albury, New South Wales, Australia

${ }^{\mathrm{b}}$ School of Biological Sciences, Victoria University of Wellington, Wellington, New Zealand

${ }^{\mathrm{bc}}$ Institute of Ecology and Biological Resources/Graduate University of Science and Technology, Vietnam Academy of Science and Technology, Hanoi 10072, Viet Nam

${ }^{\text {bd }}$ Universidade de São Paulo, Departamento de Ecologia, São Paulo, Brazil

be Institute of Natural and Environmental Sciences, University of Hyogo, Museum of Nature and Human Activities, Yayoigaoka 6, Sanda, Hyogo 669-1546, Japan

${ }^{b f}$ Faculty of Biology, Dept. of Zoology and Marine Biology, National and Kapodistrian University of Athens, Panepistimioupolis, Ilissia 15784, Athens, Greece

${ }^{b g}$ Royal Belgian Institute of Natural Sciences, Rue Vautier 29, B-1000 Brussels, Belgium

${ }^{\text {bh }}$ School of Biological Sciences, Queen's University Belfast, 19 Chlorine Gardens, Belfast BT9 5DL, United Kingdom

${ }^{b i}$ U.S. Geological Survey, Fort Collins Science Center, Fort Collins, CO, USA

${ }^{b j}$ School of Zoology and Steinhardt Museum of Natural History, Tel Aviv University, Tel Aviv, Israel

${ }^{\mathrm{bk}}$ Department of Botany and Zoology, Stellenbosch University, Stellenbosch, Western Cape 7600, South Africa

${ }^{b l}$ Department of Biology, Dalhousie University, Halifax B3H 4R2, Canada

${ }^{\mathrm{bm}}$ Department of Biochemistry, Genetics and Immunology and Biomedical Research Center (CINBIO), University of Vigo, Campus Universitario Lagoas, Marcosende, 36310 Vigo, Spain

bn Brandon University, Brandon, Manitoba R7A 6A9, Canada

bo Outwest Reptile Consulting Services, Montefiores Street, Wellington, NSW 2820, Australia

bp National Natural History Collections, The Hebrew University of Jerusalem, Israel

bq Sydney School of Veterinary Science B01, University of Sydney, NSW 2006, Australia

${ }^{b r}$ Department of Animal and Plant Sciences, University of Sheffield, Sheffield, United Kingdom

bs UNEP World Conservation Monitoring Centre, Cambridge, United Kingdom

${ }^{\text {bt }}$ Museo de Zoología, Escuela de Biología, Pontificia Universidad Católica del Ecuador, Quito, Ecuador

bu Institut de Recherche pour le Développement (IRD), UMR MIVEGEC, BP 1386 Dakar, Senegal

bv Center for Biological Data Science, Virginia Commonwealth University, Richmond, VA 23284, USA

${ }^{\text {bw }}$ Department of Biological Sciences, Faculty of Applied Sciences, Rajarata University, Mihinthale 50300, Sri Lanka

${ }^{b x}$ School of Molecular Sciences, La Trobe University, Wodonga, Victoria, Australia

by Bioresearches (Babbage Consultants), Auckland, New Zealand

bz Technische Universität Braunschweig, Zoological Institute, Mendelssohnstr. 4, 38106 Braunschweig, Germany

ca Allwetterzoo Münster, Sentruper Str 315, D48161 Münster, Germany

${ }^{\mathrm{cb}}$ School of Natural Sciences, University of Tasmania, Hobart, Tasmania, Australia

${ }^{c c}$ School of Life and Environmental Sciences, University of Sydney, NSW 2006, Australia

cd Cologne Zoo, Riehler Str. 173, D-50735 Cologne, Germany

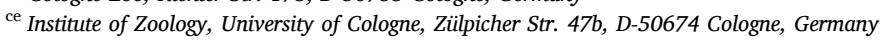

\section{A R T I C L E I N F O}

\section{Keywords:}

Extinction risk

IUCN Red List

\section{A B S T R A C T}

Our knowledge of the conservation status of reptiles, the most diverse class of terrestrial vertebrates, has improved dramatically over the past decade, but still lags behind that of the other tetrapod groups. Here, we conduct the first comprehensive evaluation ( $\sim 92 \%$ of the world's $\sim 1714$ described species) of the conservation

\footnotetext{
1 Joint senior authors.
} 
Lizard

Protected areas

Reptile

Skink

Taxonomic bias status of skinks (Scincidae), a speciose reptile family with a worldwide distribution. Using International Union for Conservation of Nature (IUCN) criteria, we report that $\sim 20 \%$ of species are threatened with extinction, and nine species are Extinct or Extinct in the Wild. The highest levels of threat are evident in Madagascar and the Neotropics, and in the subfamilies Mabuyinae, Eugongylinae and Scincinae. The vast majority of threatened skink species were listed based primarily on their small geographic ranges (Criterion B, 83\%; Criterion D2, 13\%). Although the population trend of $42 \%$ of species was stable, $14 \%$ have declining populations. The key threats to skinks are habitat loss due to agriculture, invasive species, and biological resource use (e.g., hunting, timber harvesting). The distributions of $61 \%$ of species do not overlap with protected areas. Despite our improved knowledge of the conservation status of the world's skinks, $8 \%$ of species remain to be assessed, and $14 \%$ are listed as Data Deficient. The conservation status of almost a quarter of the world's skink species thus remains unknown. We use our updated knowledge of the conservation status of the group to develop and outline the priorities for the conservation assessment and management of the world's skink species.

\section{Introduction}

"Knowledge is Power"

(Francis Bacon, 1597)

This adage is no better exemplified than in the field of conservation biology, as we cannot effectively conserve species that we do not know are threatened, and we cannot ensure the long-term persistence of threatened species unless we understand the threats that they face. This knowledge is the foundation of effective conservation policy and management (Soulé, 1985; Primack, 2014). Since 1964, the International Union for Conservation of Nature (IUCN) Red List of Threatened Species has been the primary source of this knowledge for conservation biologists internationally. Understanding the conservation status (and threats) of every known species is a key goal for conservation biologists as it would enable informed conservation planning and actions. However, there are few instances where information has been complete and subsequent management plans have been able to be effectively implemented (IUCN, 2020). Whilst terrestrial vertebrates are the world's most studied group, $\sim 25 \%$ of species remain to be assessed against IUCN Red List criteria (IUCN, 2020). Despite considerable advancement over the past few years due to the progress made in achieving the IUCN's first Global Reptile Assessment (Böhm et al., 2013; Meiri and Chapple, 2016; Tolley et al., 2016, 2019; Tingley et al., 2016, 2019; Chapple et al., 2019), reptiles remain the most under-assessed terrestrial vertebrate group, with $\sim 30 \%$ of the world's $\sim 11,350$ species unassessed by the end of 2020 (IUCN, 2020; and probably 10\% during 2021).

Here we provide the first detailed overview of the conservation assessment of skinks (Scincidae), a diverse ( $\sim 1714$ described species; Uetz et al., 2020) family of terrestrial vertebrates. Skinks represent a quarter of lizard diversity worldwide (Uetz et al., 2020). They have a near-global distribution, with species richness hotspots in Australia, New Guinea, south-east Asia, sub-Saharan Africa, and Madagascar (Fig. 1). The species richness of skinks is mirrored by their extreme morphological, ecological, and life-history diversification (Greer, 2007). For instance, skinks exhibit a 17-fold variation in adult body length and an 1800-fold difference in adult body mass (Greer, 2007; Meiri, 2018). There have been multiple cases of evolution from limbed to limb reduction and/or loss (25+ transitions; Greer, 1991), four independent origins of the enigmatic evolution of green blood (Rodriguez et al., 2018), and 31 + evolutionary shifts from oviparity to viviparity (Blackburn, 1982, 1999, 2015). Furthermore, all six of the amniote clades that have converged on the "mammalian" pattern of complex placentation and placentotrophy (except mammals) are skinks (Blackburn, 2015; Griffith and Wagner, 2017). Skinks also display considerable variation in ecological and life history traits, such as activity times, foraging mode, thermal preferences, microhabitat use, clutch (litter) size and frequency, sociality, and diet, with several species exhibiting long-term stable social aggregations (Chapple, 2003; Gardner et al., 2016; While et al., 2019) and herbivory (Chapple, 2003), which are rare in squamates in general. Worryingly, skinks, whilst comprising $24 \%$ of recognised lizard species comprise $\sim 45 \%$ of documented, presumably

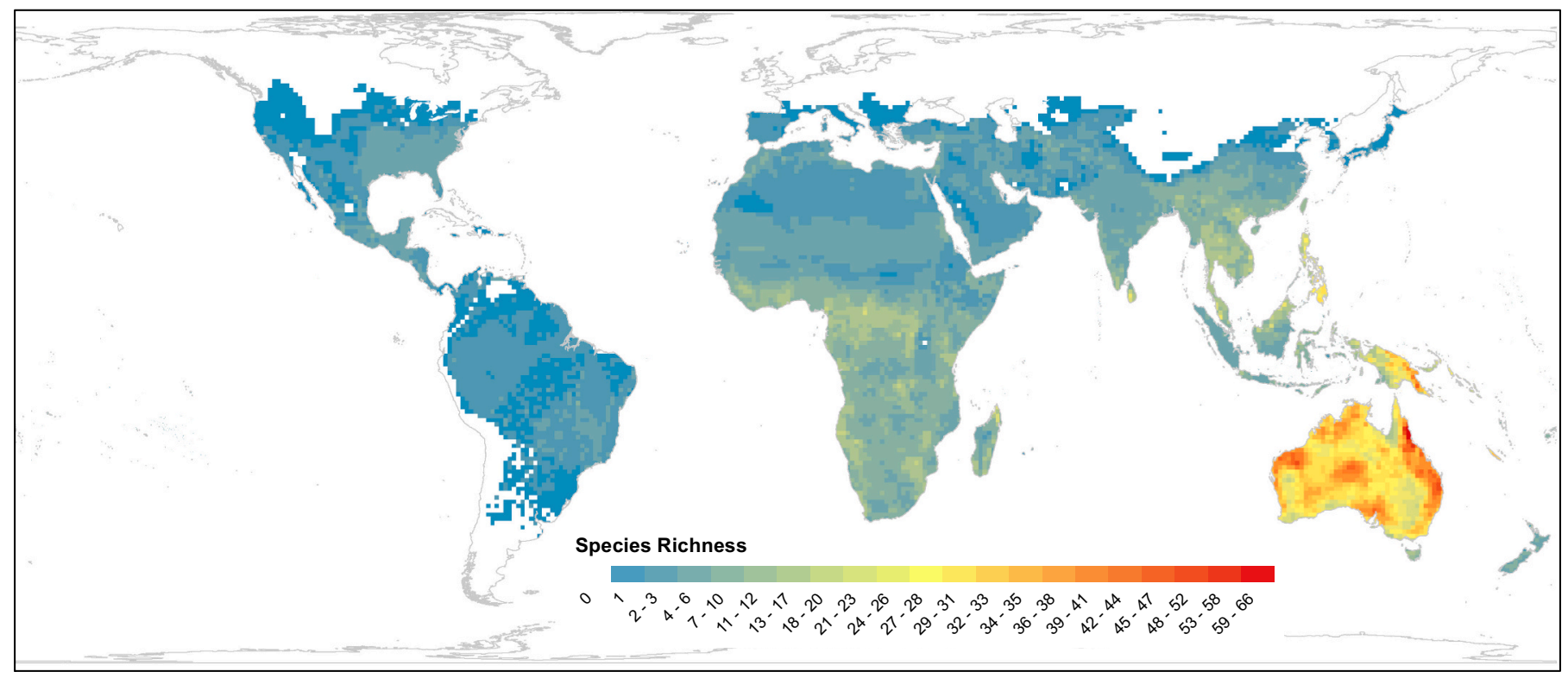

Fig. 1. Global species richness of skinks (Scincidae).

Data from Global Assessment of Reptile Distributions (GARD; http://www.gardinitiative.org/), 2019. 
human-mediated, lizard extinctions (20 of 45 species) that have occurred in the late Quaternary (Slavenko et al., 2016).

Global reptile populations are thought to have declined by $\sim 55 \%$ over the past 50 years (Saha et al., 2018). However, several factors have inhibited our ability to gauge the current conservation status of skinks. First, we are yet to fully grasp the true species richness of skinks. Skinks continue to be described at a substantial rate $(\sim 20$ species per year during the last decade, Fig. 2; Uetz et al., 2020). Skink numbers accumulate not only via the discovery and description of new species, but also through the splitting of species complexes. This means that not only do the species newly described and newly elevated from synonymy need to be assessed, but the recognised species impacted by the revision of species complexes, and the subsequent reduced geographic range of some species, need to be re-assessed (i.e. at least a 2 -fold increase in the required number of conservation assessments). Second, we have limited knowledge of the distribution, biology, and ecology of most skink species (Roll et al., 2017; Meiri, 2018; Meiri et al., 2018). This is a result of the sheer number of species to study, the fact that the major centres of skink diversity (i.e. central Australia, New Guinea, south-east Asia, central Africa; Fig. 1) are located in remote, inaccessible locations, and/ or in regions well away from areas where there are high concentrations of herpetologists (Greer, 2007; Tingley et al., 2019; Chapple et al., 2019), and limited funding for studies of basic ecology and biology (e.g. Crowther et al., 2012; Lindenmayer et al., 2012). This has limited our knowledge of skink species biology and threatening processes, which has in turn led to skinks (and squamates more broadly) having a high proportion of Data Deficient and non-assessed species (Böhm et al., 2013; Tingley et al., 2016; Meiri and Chapple, 2016; Bland and Böhm, 2016). Finally, there is relatively little information on the long-term population trends of skinks (Saha et al., 2018; Woinarski, 2018). This has led to the Red List accounts of skinks (and squamates in general) being less detailed than those of most other terrestrial vertebrate groups (e.g., birds, turtles) (Böhm et al., 2013; Tingley et al., 2016, 2019).

As a step towards rectifying these knowledge gaps, the IUCN SSC Skink Specialist Group (SSG) was established in July 2018 (http s://www.skinks.org/). The SSG currently has $\sim 160$ members, composed of a global network of biologists and wildlife managers that

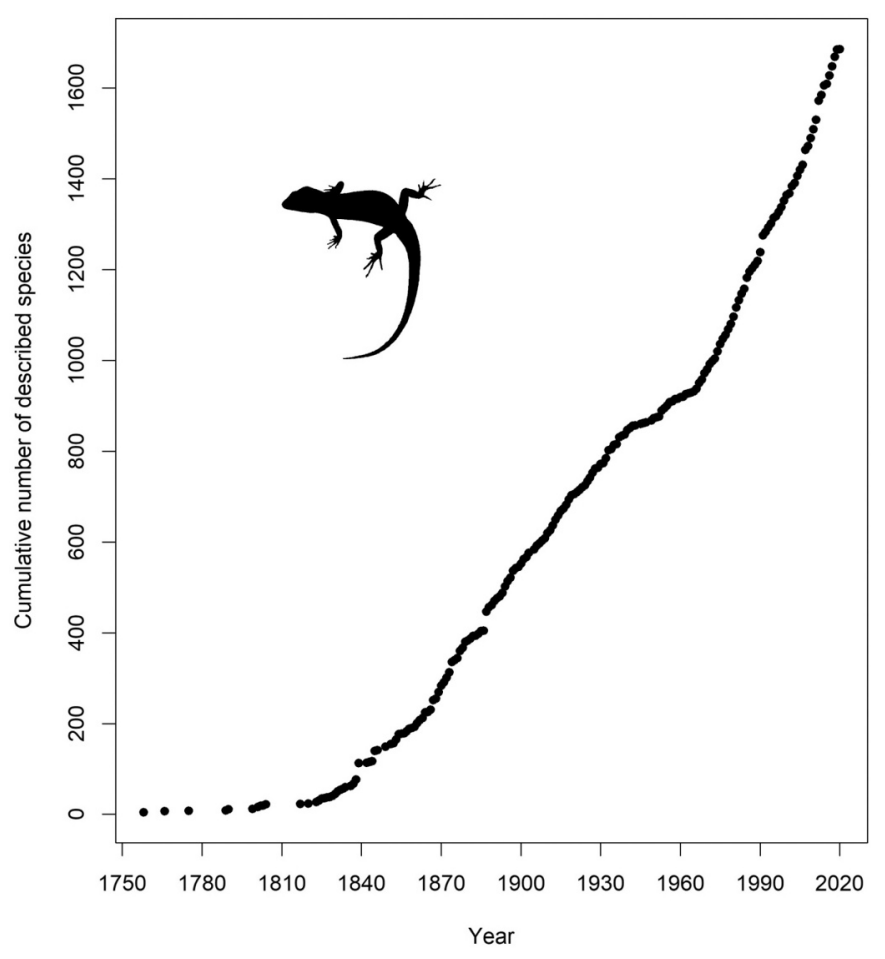

Fig. 2. Growth in currently recognised skink (Scincidae) species over time. are actively involved in research and conservation-related activities on the world's skinks. The core goals of the SSG are to (1) complete Red List assessments for all described skink species to identify threatened species, and (2) co-ordinate conservation management for threatened skink species worldwide. To achieve these goals, we conducted the first comprehensive overview of the conservation assessment of skinks worldwide. Specifically, we reviewed the current conservation status of skinks, in terms of the number of species that have been assessed, the proportion of assessed species that are threatened, and the number that remain to be assessed. To develop conservation priorities for skinks, we investigated geographic and taxonomic patterns in extinction risk and threats. Finally, we examined the degree to which threatened, Data Deficient, and Not Evaluated species overlap with protected areas. This information can be used to develop conservation plans and priorities for skinks, including a strategy to complete assessments for all described skink species globally.

\section{Materials and methods}

\subsection{Conservation status and distribution of skinks}

We used the data from all skink species that were assessed as part of the Global Reptile Assessment, which was finalised in mid-2020. After updating the list for current taxonomy (Uetz et al., 2020, and additional amendments), we used Red List assessments for 1578 skink species globally (Table 1). As at July 2020, the IUCN SSC Skink Specialist Group recognised 1714 described skink species globally. Thus, 136 species were Not Evaluated against IUCN Red List criteria (Table 1). Distributional data for all 1714 described skink species were obtained from version 1.7 of the Global Assessments of Reptile Distributions (GARD; http://www.gardinitiative.org/), which is an updated version of the datasets published in Roll et al. (2017) and Gumbs et al. (2020). The distributional patterns identified using either point locality or polygon data were concordant (Fig. S1), therefore our distributional maps and analyses are based on the polygon data from GARD. Data on the year of description for each skink species were obtained from Uetz et al. (2020). Seven monophyletic skink subfamilies are currently recognised (Acontinae, Egerniinae, Eugongylinae, Lygosominae, Mabuyinae, Scincinae, Sphenomorphinae; Hedges, 2014; Uetz et al., 2020). We examined differences in the conservation status and extinction risk among these clades.

\subsection{Estimating overall extinction risk}

Species classified as Data Deficient (DD), and those that are Not Evaluated (NE), introduce uncertainty into calculations of the percentage of threatened species (i.e. those classified as Vulnerable, Endangered, or Critically Endangered out of all species). We therefore estimated the percentage of threatened species using three different approaches to the treatment of Data Deficient species (Böhm et al., 2013; Tingley et al., 2019).

Our first approach involved assuming that the true extinction risk of Data Deficient and Not Evaluated species would fall into the three threatened categories in the same proportions as observed in currently assessed species: $(\mathrm{CR}+\mathrm{EN}+\mathrm{VU}) /(\mathrm{N}-\mathrm{EX}-\mathrm{EW}-\mathrm{DD})$, where $\mathrm{N}$ is the total number of evaluated skink species worldwide, EX and EW refer to the number of Extinct and Extinct in the Wild species, respectively, and CR, EN, VU, and DD are, respectively, the numbers of Critically Endangered, Endangered, Vulnerable, and Data Deficient species. Second, we produced an optimistic (lower bound) estimate of the percentage of threatened species by assuming that no Data Deficient and Not Evaluated species were threatened: $(\mathrm{CR}+\mathrm{EN}+\mathrm{VU}) /(\mathrm{N}+\mathrm{NE}-\mathrm{EX}-\mathrm{EW})$. Finally, we produced a pessimistic estimate by assuming that all Data Deficient and all Not Evaluated species were threatened: (CR + EN + VU $+\mathrm{DD}+\mathrm{NE}) /(\mathrm{N}+\mathrm{NE}-\mathrm{EX}-\mathrm{EW})$. Extinct and Extinct in the Wild species were excluded from spatial analyses. We calculated the Red List 
Table 1

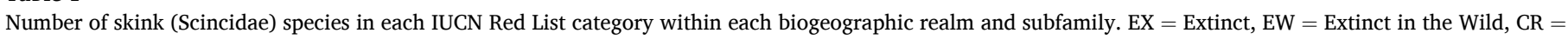

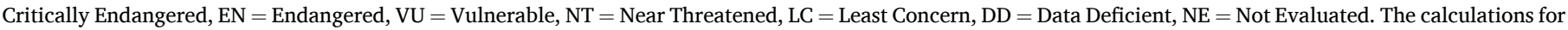

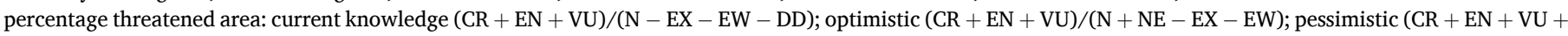

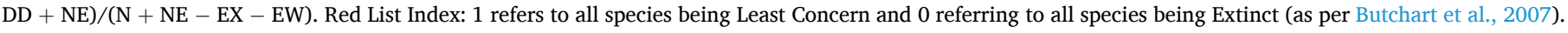

\begin{tabular}{|c|c|c|c|c|c|c|c|c|c|c|c|c|c|}
\hline & \multirow[t]{2}{*}{ EX/EW } & \multicolumn{3}{|c|}{ Threatened } & \multirow[t]{2}{*}{ NT } & \multirow[t]{2}{*}{ LC } & \multicolumn{2}{|c|}{ Non-classifiable } & \multirow[t]{2}{*}{ Total } & \multirow[t]{2}{*}{ Red List Index } & \multicolumn{3}{|l|}{$\%$ Threatened } \\
\hline & & $\mathrm{CR}$ & EN & VU & & & $\mathrm{DD}$ & $\mathrm{NE}$ & & & Current knowledge & Optimistic & Pessimistic \\
\hline \multicolumn{14}{|l|}{ Realm } \\
\hline Afrotropic & $2 / 0$ & 5 & 9 & 8 & 12 & 165 & 36 & 8 & 245 & 0.91 & $11.1 \%$ & $9.1 \%$ & $23.9 \%$ \\
\hline Australasia & $1 / 0$ & 28 & 59 & 48 & 24 & 549 & 60 & 31 & 800 & 0.9 & $19.1 \%$ & $16.9 \%$ & $24.4 \%$ \\
\hline Indomalay & $1 / 1$ & 5 & 18 & 12 & 26 & 157 & 92 & 72 & 382 & 0.88 & $16.2 \%$ & $9.2 \%$ & $33.4 \%$ \\
\hline Madagascar & $2 / 0$ & 6 & 8 & 15 & 8 & 33 & 17 & 7 & 94 & 0.74 & $42.6 \%$ & $31.5 \%$ & $50.0 \%$ \\
\hline Nearctic & 0 & 1 & 0 & 1 & 0 & 15 & 2 & 5 & 24 & 0.93 & $11.8 \%$ & $8.3 \%$ & $16.7 \%$ \\
\hline Neotropic & $2 / 0$ & 26 & 4 & 3 & 1 & 36 & 7 & 8 & 87 & 0.63 & $47.1 \%$ & $38.8 \%$ & $47.1 \%$ \\
\hline Palaearctic & 0 & 2 & 3 & 3 & 5 & 53 & 7 & 5 & 78 & 0.92 & $12.1 \%$ & $10.3 \%$ & $19.2 \%$ \\
\hline \multicolumn{14}{|l|}{ Subfamily } \\
\hline Acontinae & 0 & 0 & 0 & 0 & 1 & 27 & 3 & 0 & 31 & 0.99 & $0 \%$ & $0 \%$ & $1.3 \%$ \\
\hline Egerniinae & 0 & 1 & 4 & 2 & 3 & 44 & 4 & 4 & 62 & 0.91 & $13.0 \%$ & $11.3 \%$ & $24.2 \%$ \\
\hline Eugongylinae & $4 / 1$ & 23 & 47 & 44 & 14 & 252 & 43 & 19 & 447 & 0.81 & $30.0 \%$ & $25.8 \%$ & $39.8 \%$ \\
\hline Lygosominae & 0 & 0 & 0 & 0 & 0 & 32 & 17 & 5 & 54 & 1.00 & $0 \%$ & $0 \%$ & $40.7 \%$ \\
\hline Mabuyinae & $3 / 0$ & 27 & 10 & 11 & 8 & 121 & 22 & 20 & 222 & 0.79 & $27.1 \%$ & $21.9 \%$ & $41.1 \%$ \\
\hline Scincinae & $1 / 0$ & 13 & 21 & 19 & 23 & 137 & 39 & 40 & 293 & 0.83 & $24.9 \%$ & $18.2 \%$ & $45.2 \%$ \\
\hline Sphenomorphinae & 0 & 9 & 19 & 14 & 27 & 395 & 93 & 48 & 605 & 0.93 & $9.1 \%$ & $6.9 \%$ & $30.2 \%$ \\
\hline Overall & $8 / 1$ & 73 & 101 & 90 & 76 & 1008 & 221 & 136 & 1714 & 0.87 & $19.6 \%$ & $15.5 \%$ & $36.4 \%$ \\
\hline
\end{tabular}

Index (RLI, as per Butchart et al., 2007) for each region and subfamily. The RLI value was calculated by multiplying the number of species in each red list category by the category weight ( 0 for Least Concern [LC], 1 for Near Threatened [NT], 2 for VU, 3 for EN, 4 for CR and 5 for EX). The product of these was summed and then divided by the maximum possible product (number of species multiplied by the maximum weight of 5). This value was then subtracted from one to produce the RLI score for the group. This produces an index value that ranges from 0 to 1 , where 1 refers to all species being Least Concern and 0 refers to all species being Extinct. Population trajectories for each species were categorised according to the IUCN Red List assessments (as stable, increasing, decreasing, or unknown/not evaluated), for each skink species.

\subsection{Geographic and taxonomic patterns of extinction risk}

Species geographic range maps from GARD were overlaid on a $96.486 \mathrm{~km} \times 96.486 \mathrm{~km}$ grid in a global Behrmann equal area projection (roughly $1 * 1^{\circ}$ at the equator), to estimate spatial patterns of species richness. Our initial analyses indicated that grid size resolution did not affect species richness estimates, as previously reported by Roll et al. (2017). Maps were produced for (i) all skink species (N + NE); (ii) threatened species (CR + EN + VU); (iii) Data Deficient (DD) species; (iv) Not Evaluated (NE) species; and (v) unclassifiable (DD + NE) species. We tallied the absolute numbers of species in these categories within each grid cell. We also evaluated whether threatened species were randomly distributed among subfamilies and biogeographic realms (according to the realm definition of the World Wildlife Fund: https:// www.worldwildlife.org/biomes) using chi-square tests of independence. In addition, we examined the distribution of EDGE (Evolutionary Distinct and Globally Endangered; https://www.edgeofexistence.org/) skink species, using both the mean, and sum, EDGE score for each grid square.

\subsection{Threatening processes}

Major threats were identified for each skink species in the IUCN Red List assessments. We used these data to map the number of species threatened by the types of threat listed for the largest number of skink species: agriculture, invasive species, biological resource use (e.g., hunting and collecting of animals; logging and wood harvesting), residential and commercial development (e.g., housing and urban developments, commercial and industrial areas, tourism and recreational activities), natural systems modifications (e.g., fire and fire suppression, dams and water management/use), energy production and mining, and climate change and severe weather. We did this for all species irrespective of their IUCN status (some non-threatened species are listed as being subjected to such threats, but this is not done for all species).

\subsection{Protected area coverage}

We calculated the proportion of each species' geographic range that fell within the global protected area network, using range data from GARD and protected area data from the United Nations Environment Programme World Conservation Monitoring Centre (UNEP-WCMC, 2020) and IUCN (2020) (https://www.iucn.org/theme/protected-areas /about/protected-area-categories). We considered two types of protected areas in our analysis: (i) strict nature reserves (IUCN Category Ia Strict Nature Reserve, and Ib Wilderness Area), and (ii) reserves set aside for nature (IUCN Categories I-IV; II National Park, III Natural Monument or Feature, IV Habitat/Species Management Area). We examined geographic range overlap with both types of protected areas separately for (i) Data Deficient, (ii) threatened (VU, EN, CR), (iii) non-threatened (LC, NT), and (iv) Not Evaluated species.

\section{Results}

\subsection{Overall extinction risk}

Of the 1578 skink species that have been assessed against IUCN Red List criteria, 1008 (63.9\%) were assessed as Least Concern (Table 1). Seventy-six species (4.8\%) were classified as Near Threatened, and 264 species $(16.7 \%)$ were listed as threatened. Within the threatened categories, 73 (4.6\%) were evaluated as Critically Endangered, 101 (6.4\%) as Endangered, and 90 (5.7\%) as Vulnerable (Table 1). In addition, eight species are listed as Extinct (Alinea luciae, Chioninia coctei, Copeoglossum redondae, Emoia nativitatis, Leiolopisma ceciliae, Leiolopisma mauritianum, Scelotes guentheri, Tachygyia microlepis) and one as Extinct in the Wild (Cryptoblepharus egeriae) (Table 1). Eight of the nine species classified as Extinct or Extinct in the Wild (all except Scelotes guentheri) were endemic to islands and some of them showed remarkable island gigantism (e.g., C. coctei from Cabo Verde and L. mauritianum from Mauritius). A substantial number of species (221 species; $14.0 \%$ ) were classified as Data 
Deficient (Table 1). When combined with the 136 skink species $(7.9 \%$ of described species; as of July 2020) that are yet to be evaluated against IUCN Red List criteria, 357 species (20.8\% of described skink species) are unclassified (Table 1). The estimated total percentage of threatened (i.e. Vulnerable, Endangered or Critically Endangered) skink species is $19.6 \%$, with an optimistic estimate of $15.5 \%$ (i.e., all DD and NE species are not threatened) and a pessimistic estimate (i.e., including all DD and NE species) of $36.4 \%$ (Table 1). The overall Red List Index for skinks is 0.87 (Table 1). Population trends were assessed as stable for $41.8 \%(n=$ $657)$ of species, decreasing for $14.2 \%(n=223)$, increasing for $0.5 \%(n$ $=8)$, and unknown for $43.4 \%(n=681)$ (Table 2$)$.

The vast majority of threatened species (220 of 264 species; 83.3\%; Table 3) were classified based largely on having a restricted geographic range (Extent of Occurrence less than $20,000 \mathrm{~km}^{2}$ ), typically with an ongoing threat that further reduces this distribution, or the quality of habitat within it (IUCN Criterion B). Only ten species were classified under Criterion A (severe [ $>30 \%$ ] reductions in population size over the last ten years or three generations), and five under Criterion $\mathrm{C}$ (small population size and population decline; Bellatorias obiri, Liopholis kintorei, Oligosoma albornense, O. hoparatea, and Phoboscincus bocourti). Thirty-nine of the threatened species $(14.8 \%)$ were listed under Criterion D (generally D2 [87.2\%]: small area of occupancy or few locations, with a highly plausible near-future threat) (Table 3); thus, over $90 \%$ of threatened skink species are evaluated chiefly on the basis of their small ranges. No skink species (and indeed, only two reptile species) have been listed under Criterion E (quantitative analysis of extinction risk) (Table 3), again reflecting the overall poor knowledge of their status. Extinct and Extinct in the Wild skink species were generally described earlier than species in other Red List categories (Table 4). In contrast, Least Concern species have earlier description dates than either threatened species or Data Deficient species (Table 4), implying that species not yet described may well be threatened. Not Evaluated species have generally been described in the last 2-3 decades (Table 4).

\subsection{Geographic and taxonomic patterns of extinction risk}

Skink species richness is highest in Australia, New Guinea, south-east Asia, Pacific Islands, Madagascar, and continental Africa (Fig. 1). Whilst the geographic patterns of threat (\% threat, Red List Index) were often congruent with these diversity hotspots (i.e. New Caledonia $65 \%$ of species threatened; Madagascar, Neotropics $>40 \%$ of species threatened), other areas of species richness had lower percentages of threat (10-20\%; Afrotropics, Australasia, Indomalayan, Nearctic, Palaearctic; about $11,19,16,12$ and $12 \%$ of species threatened, respectively, $\chi^{2}=$ 69.0, $p<0.0001$ ), threat levels (Table 1; Fig. 3). The mean EDGE score was highest in Asia, India, the Middle East, northern Africa, and Madagascar (Fig. S2a). In contrast, the sum of EDGE scores was greatest in Australia, New Guinea, Asia, southern Africa, and Madagascar (Fig. S2b). Skink species richness was associated with the sum of EDGE scores (Fig. S2d), but not the mean EDGE score (Fig. S2c).

There was clear evidence for a taxonomic signal in threat, with a

Table 2

Population trends for skink (Scincidae) species that have been assigned an IUCN Red List category. $\mathrm{CR}=$ Critically Endangered, $\mathrm{EN}=$ Endangered, $\mathrm{VU}=$ Vulnerable, $\mathrm{NT}=$ Near Threatened, $\mathrm{LC}=$ Least Concern, $\mathrm{DD}=$ Data Deficient. Extinct, and Extinct in the Wild, species have been excluded. Percentages are out of the number of species in each threat category.

\begin{tabular}{lllllr}
\hline Category & Decreasing & Increasing & Stable & Unknown & Overall \\
\hline CR & $44(60.3 \%)$ & 0 & $3(4.1 \%)$ & $26(35.6 \%)$ & 73 \\
EN & $68(67.3 \%)$ & 0 & $4(4.0 \%)$ & $29(28.7 \%)$ & 101 \\
VU & $42(46.7 \%)$ & $5(5.6 \%)$ & $8(8.9 \%)$ & $35(38.9 \%)$ & 90 \\
NT & $32(42.1 \%)$ & $1(1.3 \%)$ & $17(22.4 \%)$ & $26(34.2 \%)$ & 76 \\
LC & $36(3.6 \%)$ & $2(0.2 \%)$ & $616(60.1 \%)$ & $354(35.1 \%)$ & 1008 \\
DD & $1(0.5 \%)$ & 0 & $9(4.1 \%)$ & $211(95.5 \%)$ & 221 \\
Overall & $223(14.2 \%)$ & $8(0.5 \%)$ & $657(41.8 \%)$ & $681(43.4 \%)$ & 1569 \\
\hline
\end{tabular}

Table 3

Number of threatened skink (Scincidae) species $(n=$ 264) that are listed under each IUCN Red List criterion. Note that several species are listed under multiple criteria (and hence percentages sum to $>1$ ).

\begin{tabular}{ll}
\hline Criterion & Number of species \\
\hline A & $10(3.8 \%)$ \\
B & $220(83.3 \%)$ \\
C & $5(1.9 \%)$ \\
D & $39(14.8 \%)$ \\
E & 0 \\
\hline
\end{tabular}

Table 4

Mean date of description ( \pm SE) for skink (Scincidae) species assigned to each IUCN Red List category.

\begin{tabular}{ll}
\hline IUCN Red List category & Mean year described \\
\hline Extinct (EX)/Extinct in the Wild (EW) & $1902 \pm 21.3$ \\
Critically Endangered (CR) & $1966 \pm 7.3$ \\
Endangered (EN) & $1951 \pm 5.4$ \\
Vulnerable (VU) & $1956 \pm 5.6$ \\
Near Threatened (NT) & $1946 \pm 6.6$ \\
Least Concern (LC) & $1921 \pm 1.9$ \\
Data Deficient (DD) & $1953 \pm 3.3$ \\
Not Evaluated (NE) & $1999 \pm 3.0$ \\
\hline
\end{tabular}

higher proportion of threatened species relative to the number of assessed species in Mabuyinae ( $\sim 27 \%$ threatened), Scincinae $(\sim 25 \%)$, and Eugongylinae $(\sim 30 \%)$, a lower proportion of threatened species in Egerniinae $(\sim 13 \%)$ and Sphenomorphinae $(\sim 9 \%)$ and no threatened species in the Acontinae and Lygosominae (Table $1 ; \chi^{2}=85.1, \mathrm{p}<$ 0.0001). Similarly, the Red List Index was lowest (i.e. higher extinction risk) in the Mabuyinae, Eugongylinae and Scincinae, and highest (i.e. lower extinction risk) in Acontinae and Lygosominae (Table 1).

Non-classifiable skinks, both Data Deficient and Not Evaluated species, were more commonly distributed in Australia, Africa, New Guinea, southern India, and south-east Asia (Fig. 4). Similarly, the proportion of DD and NE species was highest in the Indomalayan (42.9\%), Nearctic (29.2\%), and Madagascar (25.5\%) regions $\left(\chi^{2}=542.6, \mathrm{p}<0.0001\right.$; Table 1). Non-classifiable species were a common feature of all skink subfamilies $(9.7-40.7 \%$ of species), but highest in Lygosominae (40.7\%), Scincinae (26.9\%), and Sphenomorphinae $(23.3 \%)\left(\chi^{2}=41.9\right.$, $\mathrm{p}<0.0001$; Table 1).

\subsection{Threatening processes}

Agriculture (including land clearing for crops, plantations, and livestock) is the most prevalent threat to skinks worldwide $(25.1 \%$ of species, $n=396$ ), followed by invasive and other problematic species and diseases $(16.7 \%, n=263)$ and biological resource use $(15.0 \%, n=$ 236). The other relevant threats to skinks include residential and commercial development $(10.8 \%, n=170)$, natural systems modifications (9.4\%, $n=148)$, energy production and mining $(6.8 \%, n=107)$, and climate change and severe weather events $(4.0 \%, n=63)$.

Effects of agriculture were most common in Madagascar, Australia, New Caledonia, New Zealand, and south-east Asia (Fig. 5a). The impacts of invasive species and natural systems modifications were most pronounced in Australasia (Australia, New Caledonia, New Zealand; Fig. 5b, e), whereas biological resource use was most widespread in Madagascar and south and south-east Asia (Fig. 5c). Effects of residential and commercial development were most prevalent in Australia (especially the south-east and south-west regions), the Indo-Malay, and northern Africa (Fig. 5d). The impacts of mining and energy production were most pronounced in Australasia (Australia, New Caledonia, New Zealand) and Madagascar (Fig. 5f). 


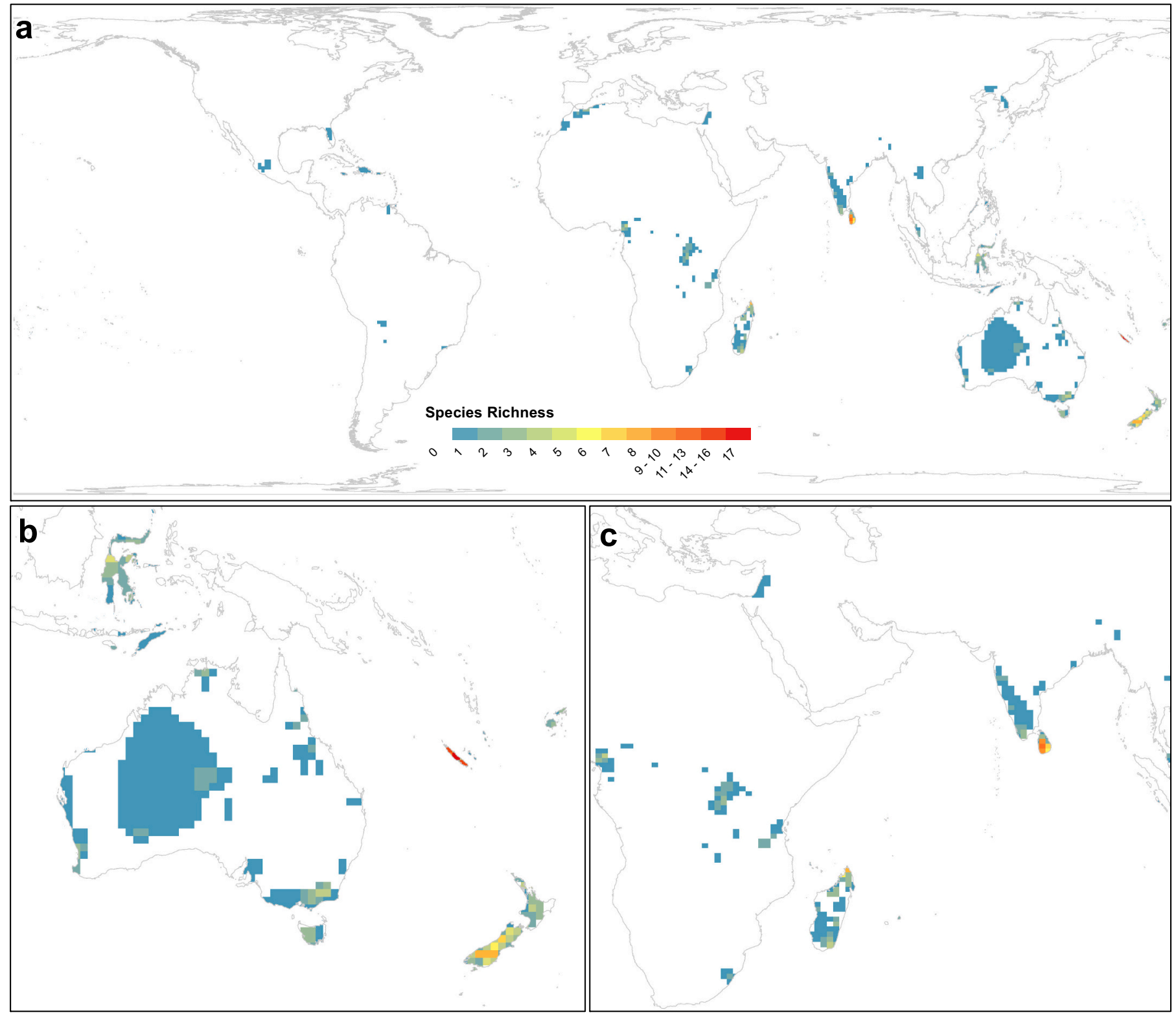

Fig. 3. Species richness of threatened skinks (Scincidae) (A) globally, and in richness hotspots in (B) Australia and New Zealand (note New Caledonia), and (C) Madagascar and South Asia (Sri Lanka and Peninsular India).

Data from Global Assessment of Reptile Distributions (GARD; http://www.gardinitiative.org/), 2019.

\subsection{Protected area coverage}

The results of our analyses revealed that distributions of skink species had little overlap with protected areas. The proportion of each species' geographic range that overlapped the global protected area network did not vary substantially among species listed under the different IUCN Red List categories, regardless of whether we examined strict nature reserves (IUCN Category I; Fig. S3A), or all reserves set aside for nature (IUCN Categories I-IV; Fig. S3B). In fact, $80 \%$ of species did not occur in a single strict nature reserve, and $61 \%$ of species did not occur in a single reserve set aside for nature. The number of species that did not overlap any protected area was similarly quite consistent among species listed under the different IUCN Red List categories (Table 5), although non-evaluated species tended to be the most poorly represented group.

\section{Discussion}

We conducted the first comprehensive analysis ( $~ 92 \%$ of the world's 1714 described species) of the conservation status of skinks, finding that one in five species are threatened with extinction, and nine species are Extinct or Extinct in the Wild. Taxonomic and geographic patterns are clearly evident, with higher levels of threat in New Caledonia and Madagascar (including the Mascarene Islands); for the latter it is where many skinks are microendemic, fossorial, and specialize on threatened habitats such as dry forest with sandy soil, or primary rainforest. Threat levels were also high in the Neotropics, although this region is generally skink-poor. Extinction risk was also higher in the subfamilies Mabuyinae, Eugongylinae, and Scincinae (Table 1). The vast majority of threatened skink species (96\%) were listed based primarily on a restricted geographic range and a current, or inferred, threat (Criteria B, and D2). Although the population trend of $\sim 42 \%$ of the species is stable, information on temporal trends in population size (or a suitable proxy) of $\sim 43 \%$ of species is unknown (Table 2 ). Around $14 \%$ of skink species 


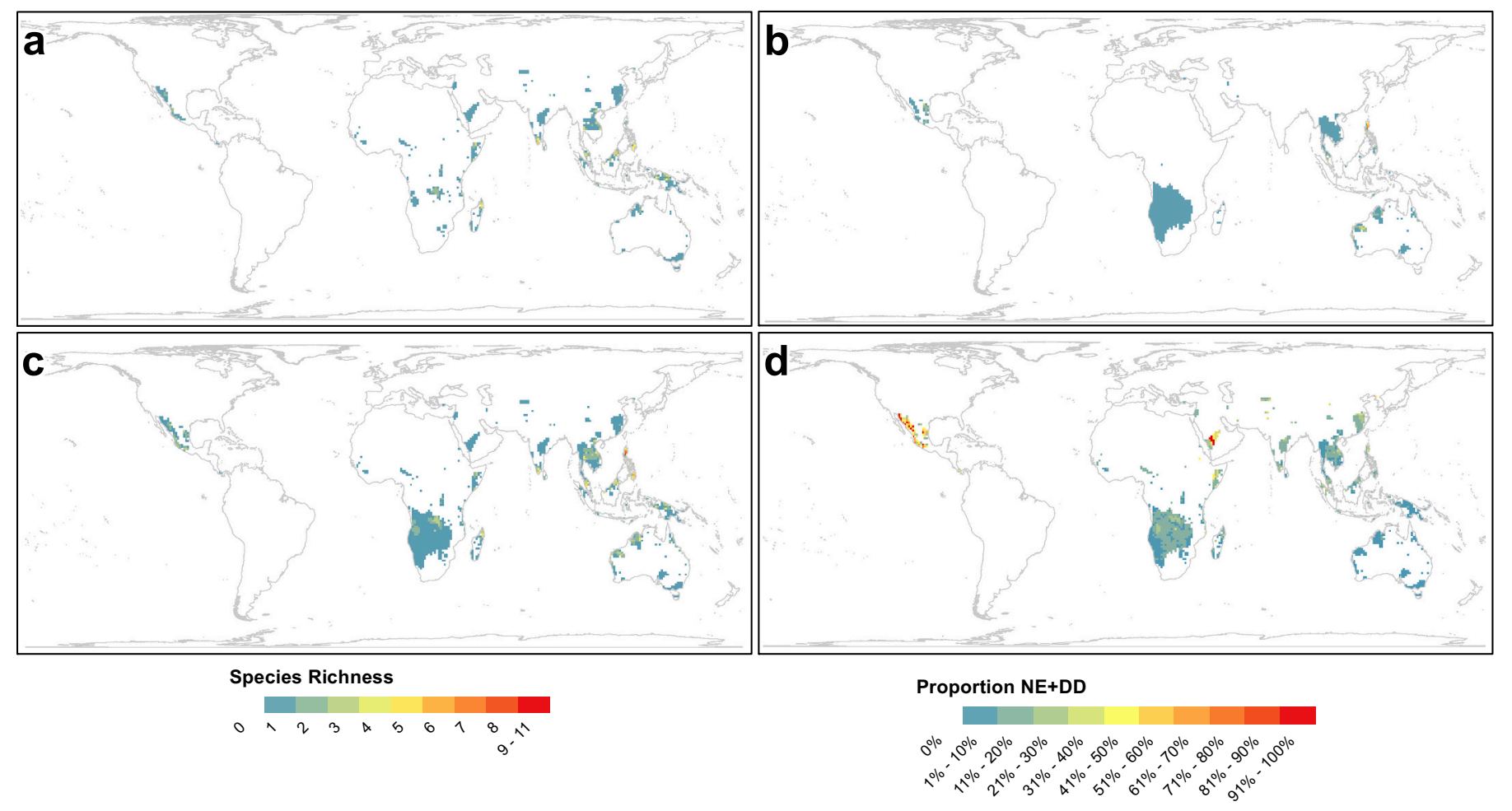

Fig. 4. Species richness of skinks (Scincidae) listed as (A) Data Deficient, (B) Not Evaluated, or (C) non-classifiable (i.e. DD + NE), and (D) proportion of nonclassifiable species out of all skink species.

Data from Global Assessment of Reptile Distributions (GARD; http://www.gardinitiative.org/), 2019.

were found to have decreasing populations, with the key threats to skinks identified as agriculture, invasive species, and biological resource use. Using a conservative protected area definition (IUCN Categories I-IV), $61 \%$ of species did not overlap a single protected area. Despite our improved knowledge of the conservation status of the world's skinks, a substantial 'assessment gap' remains (e.g., Meiri and Chapple, 2016), with $8 \%$ of species yet to be assessed against IUCN Red List criteria. When combined with the $14 \%$ listed as Data Deficient, the conservation status of almost a quarter of the world's skink species remains unknown. Below we elaborate on the findings of our study, and outline priorities for the conservation assessment and management of the world's skinks.

\subsection{One in five skink species threatened with extinction}

We found that $\sim 20 \%$ (optimistic-pessimistic range $\sim 16-36 \%$ ) of the world's skink species are currently threatened with extinction. This level of threat is consistent with the global average for reptiles $(\sim 18-19 \%$, Böhm et al., 2013; IUCN, 2020), and less than that documented for reptiles in Madagascar (39\%, Jenkins et al., 2014), but substantially higher than that reported for squamate reptiles in Australia (7.1\%; Tingley et al., 2019; Chapple et al., 2019) and South Africa (5.4\%, Tolley et al., 2019). Relative to other terrestrial vertebrate groups, the proportion of threatened skink species is greater than that reported for birds (14\%), but, if most DD species are safe, lower than that recorded for mammals (25\%) and amphibians (41\%) (IUCN, 2020). Importantly, data reveal that nine skink species are now listed as extinct (either EX or EW). Slavenko et al. (2016) reported that skinks accounted for $45 \%$ (20 of 45 species) of lizard extinctions that have occurred during the late Quaternary, with most of these occurring in the Caribbean. As the IUCN only considers species that have gone extinct since 1500, the number of extinct skink species reported here is likely conservative. Indeed, 18 skink species (Alinea lanceolata, Capitellum mariagalantae, C. metallicum, C. parvicruzae, Mabuya cochonae, M. grandisterrae, M. guadeloupae, M. hispaniolae, M. mabouya, M. montserratae, Oligosoma infrapunctatum,
Spondylurus anegadae, S. haitiae, S. lineolatus, S. magnacruzae, S. martinae, S. monitae, S. spilonotus) are currently listed as Critically Endangered (possibly extinct). The last confirmed sighting of these species varies from 1830 to 2000 (mean $1924 \pm 13$ years; see Meiri et al., 2018). Thus, further field surveys of these species will likely reveal that the true number of extinct skink species is higher than that currently reported.

Agriculture, invasive species, and biological resource use represent the three main threats to the persistence of skink species worldwide. Two of these processes, agriculture and biological resource use, also represent key threats to reptiles more broadly (Böhm et al., 2013). We found that the impacts of agriculture on skinks were most pronounced in Madagascar, Australasia (including New Zealand and New Caledonia), and Indo-Malay (Fig. 5a). This detrimental impact of agriculture has previously been reported for Australian squamates (Tingley et al., 2019; Chapple et al., 2019) and African reptiles (Tolley et al., 2016). Similarly, we found that biological resource use effects on skinks (e.g., hunting and collecting of animals; logging and wood harvesting) were most pronounced in Madagascar and south-east Asia (Fig. 5c), which is consistent with previous reports of high rates of biological resource use impacting reptiles in these regions (Böhm et al., 2013; Jenkins et al., 2014). The impact of invasive species on skinks appears to be greatest in Australasia (Fig. 5b), which is supported by several regional reptile assessments that have highlighted invasive species (e.g., invasive mammals, cane toads, weeds; Woinarski et al., 2018) as a key correlate of elevated extinction risk in Australia (Tingley et al., 2019; Chapple et al., 2019), and New Zealand (Tingley et al., 2013). Some of the four secondary threats that were identified for skinks globally (residential and commercial development, natural systems modifications, energy production and mining, climate change), have previously been identified as threats for reptiles globally (urban development, natural resource modification; Böhm et al., 2013), and for Australian squamates (natural systems modifications, energy production and mining, climate change; Tingley et al., 2019). Thus, the threats to skinks are consistent with those reported for 


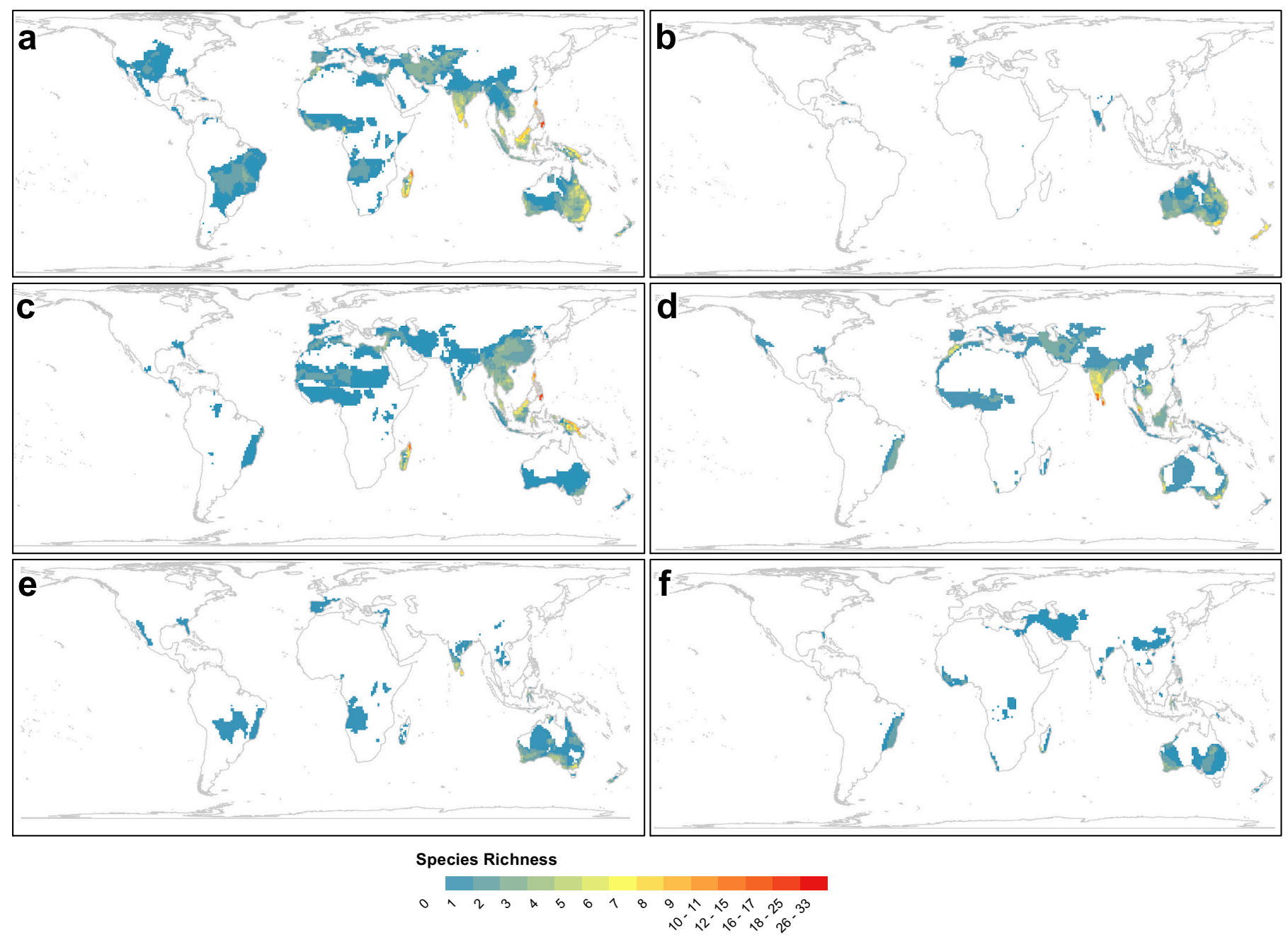

Fig. 5. The distribution of species threatened by each threat type: (A) agriculture, (B) invasive species, (C) biological resource use, (D) residential and commercial development, (E) natural systems modifications, and (F) energy production and mining.

Data from GARD (http://www.gardinitiative.org/), 2019.

Table 5

Number and percentage of species' ranges that do not overlap a single protected area.

\begin{tabular}{lllcl}
\hline IUCN category & $\begin{array}{l}\text { Species not in strict nature } \\
\text { reserves }\end{array}$ & $\begin{array}{l}\text { Percentage not in strict nature } \\
\text { reserves }\end{array}$ & $\begin{array}{l}\text { Species not in reserves set aside for } \\
\text { nature }\end{array}$ & $\begin{array}{l}\text { Percentage not in reserves set aside for } \\
\text { nature }\end{array}$ \\
\hline $\begin{array}{l}\text { Critically } \\
\text { Endangered }\end{array}$ & 65 & 89.0 & 46 & 63.0 \\
Endangered & 77 & 76.2 & 67 & 66.3 \\
Vulnerable & 68 & 75.6 & 55 & 61.1 \\
Near Threatened & 64 & 84.2 & 38 & 50.0 \\
Least Concern & 765 & 76.5 & 576 & 69.3 \\
Data Deficient & 190 & 88.4 & 149 & 71.3 \\
Not Evaluated & 96 & 95.0 & 72 & \\
\hline
\end{tabular}

reptiles more broadly on both local and global scales.

Worryingly, we found that protected areas offer little reprieve from the aforementioned threats, with $61 \%$ (IUCN categories I-V) to $80 \%$ (IUCN categories I) of species not known to occur in a single protected area. These figures are much higher than reported for Australian squamates (Tingley et al., 2019) and South African reptiles (using interpreted distribution rather than EOO; Tolley et al., 2019). Lack of overlap with protected areas may be underestimated in some rare cases when using species' extent of occurrence maps (such as those used here), due to spatial inaccuracies in defined range boundaries. However, extent of occurrence maps can also overestimate protected area coverage because such maps overestimate true species' distributions (Jetz et al., 2008). The relative magnitude of these two types of errors remains unknown, as densely sampled point locality data, and area of occupancy maps, are unavailable for squamates globally. Our results indicate that the global protected area network is currently insufficient to conserve most skink species.

\subsection{Taxonomic and geographic biases}

There was clear evidence of bias in extinction risk (e.g., percentage of species threatened, Red List Index) among skink subfamilies, with no 
threatened species in Acontinae and Lygosominae, but $>25 \%$ of species in three other subfamilies (Eugongylinae, Mabuyinae, Scincinae) being listed as threatened (Table 1). Different taxa often vary in key intrinsic (e.g., body size, life history, habitat use and preferences) and extrinsic traits (e.g. geographic range size) linked to extinction risk (Böhm et al., 2016). This could explain why taxonomic biases in threat are regularly reported in vertebrates (Böhm et al., 2013; Tolley et al., 2016; Ducatez and Shine, 2017; but see Tingley et al., 2019). Indeed, the Acontinae have a distinctly different morphology and ecology compared to most other skink subfamilies, with all members completely limbless and having a fossorial lifestyle (Pianka and Vitt, 2003; Greer, 2007; Uetz et al., 2020). Many members of the Lygosominae also exhibit limb reduction and are fossorial (Meiri, 2018; Uetz et al., 2020). However, unlike Acontinae, Lygosominae, whilst overall a small subfamily (54 species), had a high proportion of Data Deficient and Not Evaluated species (41\%; Table 1); therefore, the low extinction risk for this subfamily could merely reflect a lack of knowledge rather than the absence of threat.

Geographic biases in the extinction risk (e.g., percentage of species threatened, Red List Index) of skinks were evident, with threat hotspots ( $>40 \%$ threatened species) in the Neotropics and Madagascar, and lower threat levels in the Afrotropics, Indomalayan, Palaearctic, Nearctic, and Australasian regions. These threat hotspots have previously been identified in global (Böhm et al., 2013), and regional (Jenkins et al., 2014), reptile conservation assessments. Indeed, these regions generally have high mean EDGE scores (Fig. S2a). Conversely, whilst previous reptile assessments have identified Australia as having below average levels of extinction risk (Tingley et al., 2019), contrary to our findings, a previous global analysis identified the Oriental and Afrotropical realms as conservation hotspots (Böhm et al., 2013). Interestingly, the overall low level of threat in the Australasian realm may reflect the large number of skink species ( $27 \%$ of the global tally), and relatively low level of threat (also see Tingley et al., 2019) in Australia, obscuring the high threat level that is evident in New Zealand (74\% of species threatened, $n=50$; also see Tingley et al., 2013) and New Caledonia ( $57 \%$ species threatened, $n=68$ ). Thus, in some instances, a finer scale analysis is required to identify geographic bias in threat among skinks.

\subsection{Skink conservation hindered by a lack of knowledge}

We lack detailed knowledge on many skink species, with $14 \%$ of assessed species listed as Data Deficient. The dearth of information available for many skink species is further exemplified by the fact that the vast majority ( $\sim 95 \%)$ are listed under Criteria B and D2 (geographic range size), and population trends are unknown for $\sim 43 \%$ of assessed species. Thus, the true conservation status of the world's skinks may actually be worse than that presented in this analysis. Indeed, Saha et al. (2018) reported that reptile populations had decreased by $\sim 55 \%$ over the past 50 years. However, Bland and Böhm (2016) estimated that $\sim 19 \%$ of Data Deficient reptiles are likely to be threatened, which represents roughly the same threat level that has been reported for both reptiles more broadly (Böhm et al., 2013), and skinks (this study). However, Meiri (2016) reported that lizard species described in the 21st Century are more likely to have smaller geographic ranges and are more likely to be threatened. Gumbs et al. (2020) found that Data Deficient species group with threatened species in terms of range sizes, irreplaceability, and phylogenetic uniqueness - and that when ranking threats to reptiles independently of the IUCN process, Data Deficient species were among the most threatened. Thus, as our study finds that skink species that are yet to be assessed against Red List criteria have been described relatively recently (Table 4), and that a substantial number are listed as Data Deficient, the proportion of threatened skink species might actually be higher than we report here. Taxonomic and geographic biases are also evident for non-classifiable (i.e. Data Deficient and Not Evaluated species) skink species. Such species are more likely to occur in Africa and south-east Asia, and are more prevalent in Lygosominae (41\%), Scincinae (27\%) and Sphenomorphinae (23\%). Thus, much research is still required to redress these knowledge gaps that are evident in skinks and this represents a key priority in order to better inform conservation management of the group.

\subsection{A lingering 'assessment gap' and the need for re-assessments}

The IUCN's first Global Reptile Assessment (GRA) has been responsible for bridging the 'assessment' gap in skinks, decreasing the number of unassessed species from 66\% in 2016 (1046 of 1588 species, Meiri and Chapple, 2016) to just $8 \%$ in 2020 (136 of 1714 species, this study). But whilst the first GRA has recently concluded (though not yet published), much work remains to be done in order to ensure that all described skink species are assessed against Red List criteria. Firstly, the IUCN recommends that Red List assessments are updated every ten years (IUCN, 2020). As of July 2020, 9\% (145 species) of skink assessments are already older than ten years, and a further $12 \%$ (190 species) will reach this timepoint over the next three years. Second, $\sim 20$ new skink species are described each year (Fig. 2; Uetz et al., 2020). Whilst some of these new species represent newly discovered species, many are the result of the splitting of existing species complexes into two or more species, making the assessments of the "parent" species immediately obsolete. For example, Singhal et al. (2018) conducted a taxonomic revision of three skink species in North Queensland, Australia, splitting Lampropholis coggeri (into L. coggeri, L. similis, L. elliotensis), L. robertsi (into $L$. robertsi, L. bellendenkerensis) and Carlia rubrigularis (into C. rubrigularis, C. crypta) into multiple species. This requires both the assessment of the conservation status of the four new species, but also reassessment of the three species from which the new species were split (Chapple et al., 2019). Unfortunately, the GRA process has not fully kept track of the species impacted by such species descriptions, and thus we currently have a poor understanding of how many skink assessments have been rendered prematurely obsolete by this taxonomic activity. Finally, $14 \%$ of assessed skink species are assessed as Data Deficient. These species are missing from many efforts to conserve biodiversity as we have insufficient knowledge to assess their risk of extinction or apply conservation efforts. Thus, such species would ideally be re-assessed more frequently than every ten years to determine whether our knowledge has improved to the extent that an appropriate Red List category can be assigned. Over the next three years, some form of assessment activity is needed for $\sim 782$ skink species (136 Not Evaluated, 335 re-assessments, $\sim 60$ new species, $\sim 30$ species impacted by taxonomic activity, 221 Data Deficient species; $55 \%$ of the entire known diversity).

\section{Conclusions}

Given the context outlined in this study, the IUCN SSC Skink Specialist Groups' (SSG) goal of attaining up-to-date assessments for all described skink species represents an ambitious target. However, this goal constitutes a vital first step in improving the conservation management of the world's skinks, as it provides essential knowledge and information on extinction risk, in the universal 'language' (i.e. IUCN Red List) used by conservation biologists worldwide. In order to achieve this goal, the SSG aims to (i) assess all Not Evaluated species within the next three years, (ii) assess newly described species, and re-assess species impacted by taxonomic activity, within 12 months of the species description, (iii) re-assess Data Deficient species every 3-5 years (rather than ten years), and (iv) ensure that all skink species are assessed at least once every ten years.

The SSG has a worldwide team of global experts ( $~ 160$ members, assisted by volunteers) to assist in achieving this goal. In addition, the SSG has clearly outlined key information that it recommends be included in taxonomic papers to facilitate the rapid Red-Listing of newly described species (Fig. 6). This includes 1. A clear description of the 


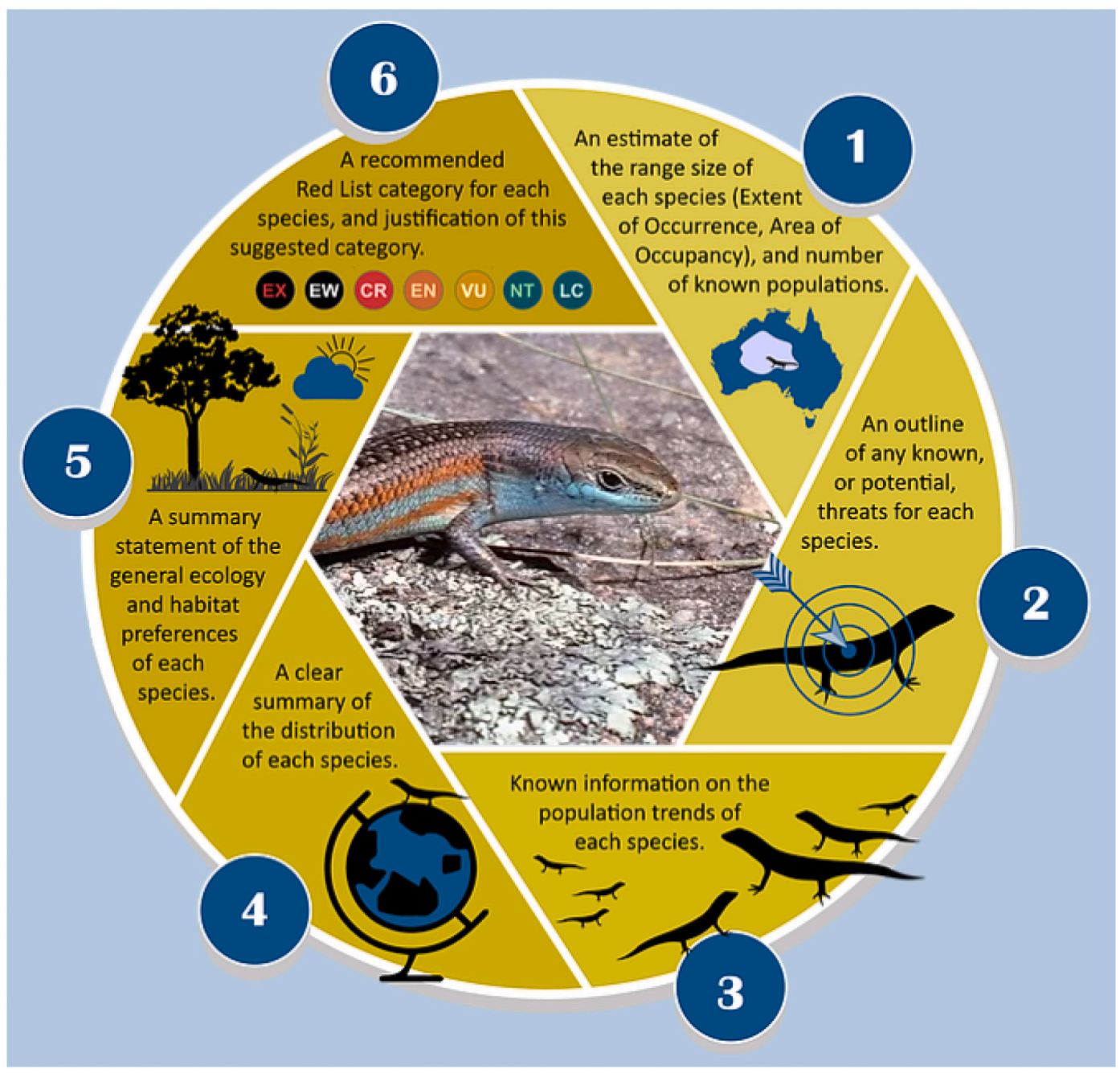

Fig. 6. A summary of the key information that the IUCN SSC Skink Specialist Group has recommended to be included in each taxonomic paper to facilitate the rapid Red Listing of newly described skink species.

species distribution, and estimates of range size such as extent of occurrence (the area of a minimum convex polygon around all known localities, which can be calculated using online tools, e.g., http://geocat. kew.org/), and the number of unique locations (which can be used to calculate area of occupancy, according to the IUCN guidelines this is the number of $2 \times 2 \mathrm{~km}$ cells occupied by a species). 2 . A list of potential threats to the species. 3. Population trend, if known (decreasing, stable, increasing or unknown). 4. A clear summary of the distribution of each species. 5. A summary of the species' general ecology (e.g., diel activity rhythm, diet and foraging strategy), life history (e.g., fecundity, reproductive mode), habitat (e.g., tropical rain forest, desert etc.), and microhabitat preferences (e.g., fossorial, arboreal, terrestrial). 6. A recommended Red-List category (Fig. 6). Complete assessment of all skinks can provide the necessary starting point from which to facilitate the other core roles of the SSG, namely to (i) co-ordinate conservation management for threatened skink species worldwide; (ii) foster collaborative research on skinks, including studies of the factors influencing their extinction risk; (iii) promote priority research actions on Threatened and Data Deficient skink species; and (iv) initiate and facilitate communication and collaboration among skink researchers and conservation managers worldwide.

\section{CRediT authorship contribution statement}

DGC, RT and SM conceived the project idea based on the work of the members of the IUCN SSC Skink Specialist Group and GARD group. DGC, RT, SM, UR and MB conducted the analyses. DGC, RT and SM wrote the manuscript. All co-authors provided comments and input into the manuscript.

\section{Declaration of competing interest}

We have no competing interests to declare.

\section{Acknowledgements}

We thank Neil Cox and Craig Hilton-Taylor for providing assistance throughout this study. Funding was provided from the Australian Friends of Tel Aviv-Monash University Research Collaboration Award (to DGC and SM), the Australian Research Council (LP170100012 to DGC and SM; FT200100108 to DGC), an IUCN Species Survival Commission Internal Grant (to DGC and SM), and Israel Science Foundation (406/19; to SM and UR), and a grant from the Rufford Foundation (to Monika Böhm). Any use of trade, firm or product names is for descriptive purposes only and does not imply endorsement by the U.S. Government.

\section{Appendix A. Supplementary data}

Supplementary data to this article can be found online at https://doi. org/10.1016/j.biocon.2021.109101. 


\section{References}

Blackburn, D.G., 1982. Evolutionary origins of viviparity in the Reptilia. 1. Sauria. Amphibia-Reptilia 3, 185-205.

Blackburn, D.G., 1999. Are viviparity and egg-guarding evolutionarily labile in squamates? Herpetologica 55, 556-573.

Blackburn, D.G., 2015. Evolution of viviparity in squamate reptiles: reversibility reconsidered. J. Exp. Zool. B Mol. Dev. Evol. 324, 473-486.

Bland, L.M., Böhm, M., 2016. Overcoming data deficiency in reptiles. Biol. Conserv. 204A, 16-22.

Böhm, M., Collen, B., Baillie, J.E., Bowles, P., Chanson, J., Cox, N., Hammerson, G., Hoffmann, M., Livingstone, S.R., Ram, M., Rhodin, A.G., et al., 2013. The conservation status of the world's reptiles. Biol. Conserv. 157, 372-385.

Böhm, M., Williams, R., Bramhall, H.R., McMillan, K.M., Davidson, A.D., Garcia, A., Bland, L.M., Bielby, J., Collen, B., 2016. Correlates of extinction risk in squamate reptiles: the relative importance of biology, geography, threat and range size. Glob. Ecol. Biogeogr. 25, 391-405.

Butchart, S.H.M., Akcakaya, H.R., Chanson, J., Baillie, J.E.M., Collen, B., Quader, S., Turner, T.R., Amin, R., Stuart, S.N., Hilton-Taylor, C., 2007. Improvements to the Red List Index. PLoS One 2, e140.

Chapple, D.G., 2003. Ecology, life-history, and behavior in the Australian Scincid genus Egernia, with comments on the evolution of complex sociality in lizards. Herpetol. Monogr. 17, 145-180.

Chapple, D.G., Tingley, R., Mitchell, N.J., Macdonald, S.L., Keogh, J.S., Shea, G.M., Bowles, P., Cox, N.A., Woinarski, J.C.Z., 2019. The Action Plan for Australian Lizards and Snakes 2017. CSIRO Publishing, Clayton.

Crowther, M.S., Lunney, D., Parnaby, H., 2012. Are journal impact factors another key threatening process for Australian fauna? In: Banks, Peter, Lunney, Daniel, Dickman, Chris (Eds.), Science under Siege: Zoology under Threat. Royal Zoological Society of New South Wales, Mosman, NSW, Australia, pp. 134-139. https://doi. org/10.7882/FS.2012.049, 2012.

Ducatez, S., Shine, R., 2017. Drivers of extinction risk in terrestrial vertebrates. Conserv. Lett. 10, 186-194.

Gardner, M.G., Pearson, S.K., Johnston, G.R., Schwarz, M.P., 2016. Group living in squamate reptiles: a review of evidence for stable aggregations. Biol. Rev. 91, 925-936.

Greer, A.E., 1991. Limb reduction in squamates: identification of the lineages and discussion of the trends. J. Herpetol. 25, 166-173.

Greer, A.E., 2007. The biology and evolution of scincid lizards. Available from. htt ps://www.academia.edu/35305801/The_Biology_and_Evolution_of_Scincid_Lizards. doc.

Griffith, O.W., Wagner, G.P., 2017. The placenta as a model for understanding the origin and evolution of vertebrate organs. Nat. Ecol. Evol. 1, 0072.

Gumbs, R., Gray, C., Böhm, M., Hoffmann, M., Grenyer, R., Jetz, W., Meiri, S., Roll, U., Owen, N., Rosindell, J., 2020. Global priorities for conservation of reptilian phylogenetic diversity in the face of human impacts. Nat. Commun. https://doi.org/ 10.1038/s41467-020-16410-6.

Hedges, S.B., 2014. The high-level classification of skinks (Reptilia, Squamata, Scincomorpha). Zootaxa 3765, 317-338.

IUCN, 2020. The IUCN Red List of Threatened Species. Version 2020-1. https://www. iucnredlist.org.

Jenkins, R.K.B., Tognelli, M.F., Bowles, P., Cox, N., Brown, J.L., et al., 2014. Extinction risks and the conservation of Madagascar's reptiles. PLoS One 9, e100173.

Jetz, W., Sekercioglu, C.H., Watson, J.E.M., 2008. Ecological correlates and conservation implications of overestimating species geographic ranges. Conserv. Biol. 22, 110-119.

Lindenmayer, D.B., Gibbons, P., Bourke, M.A., Burgman, M., Dickman, C.R., Ferrier, S., Fitzsimons, J., Freudenberger, D., Garnett, S.T., Groves, C., Hobbs, R.J., 2012. Improving biodiversity monitoring. Aust. Ecol. 37, 285-294.

Meiri, S., 2016. Small, rare and trendy: traits and biogeography of lizards described in the 21st century. J. Zool. 299, 251-261.

Meiri, S., 2018. Traits of lizards of the world: variations around a successful evolutionary design. Glob. Ecol. Biogeogr. 27, 1168-1172.

Meiri, S., Chapple, D.G., 2016. Biases in the current knowledge of threat status in lizards, and bridging the 'assessment gap'. Biol. Conserv. 204A, 6-15.

Meiri, S., Bauer, A.M., Allison, A., Castro-Herrera, F., Chirio, L., Colli, G.R., Das, I., Doan, T.M., Glaw, F., Grismer, L.L., Hoogmoed, M., Kraus, F., LeBreton, M.,
Meirte, D., Nagy, Z.T., Nogueira, C.C., Oliver, P., Pauwels, O.S.G., PincheiraDonoso, D., Shea, G., Sindaco, R., Tallowin, O.J.S., Torres-Carvajal, O., Trape, J.-F., Uetz, P., Wagner, P., Wang, Y., Ziegler, T., Roll, U., 2018. Extinct, obscure or imaginary: the lizard species with the smallest ranges. Divers. Distrib. 24, 262-273.

Pianka, E.R., Vitt, L.J., 2003. Lizards: Windows to the Evolution of Diversity. University of California Press, Berkeley.

Primack, R.B., 2014. Essential of Conservation Biology, Sixth edition. Sinauer Associates, Sunderland Massachusetts, USA.

Rodriguez, Z.B., Perkins, S.L., Austin, C.C., 2018. Multiple origins of green blood in New Guinea lizards. Sci. Adv. 4, eaao5017.

Roll, U., Feldman, A., Novosolov, M., Allison, A., Bauer, A., Bernard, R., Böhm, M., Chirio, L., Collen, B., Colli, G.R., Dabul, L., Das, I., Doan, T., Grismer, L., Herrera, F. C., Hoogmoed, M., Itescu, Y., Kraus, F., LeBreton, M., Lewin, A., Martins, M., Maza, E., Meirte, D., Nagy, Z., Nogueira, C.C., Pauwels, O.S.G., PincheiraDonoso, D., Powney, G., Sindaco, R., Tallowin, O., Torres-Carvajal, O., Trape, J.F., Uetz, P., Vidan, E., Wagner, P., Wang, Y.Z., Orme, D., Grenyer, R., Meiri, S., 2017. The global distribution of tetrapods reveals a need for targeted reptile conservation. Nat. Ecol. Evol. 1, 1677-1682.

Saha, A., McRae, L., Dodd, C.K., Gadsden, H., Hare, K.M., Lukoschek, V., Böhm, M., 2018. Tracking global population trends: population time-series data and a Living Plant Index for Reptiles. J. Herpetol. 52, 259-268.

Singhal, S., Hoskin, C.J., Couper, P., Potter, S., Moritz, C., 2018. A framework for resolving cryptic species: a case study from the lizards of the Australian wet tropics. Syst. Biol. 67, 1061-1075.

Slavenko, A., Tallowin, O.J.S., Itescu, Y., Raia, P., Meiri, S., 2016. Late Quaternary reptile extinctions: size matters, insularity dominates. Glob. Ecol. Biogeogr. 25, 1308-1320.

Soulé, M.E., 1985. What is conservation biology? A new synthetic discipline addresses the dynamics and problems of perturbed species, communities, and ecosystems. BioScience 25, 727-734.

Tingley, R., Hitchmough, R.A., Chapple, D.G., 2013. Life-history traits and extrinsic threats determine extinction risk in New Zealand lizards. Biol. Conserv. 165, 62-68.

Tingley, R., Meiri, S., Chapple, D.G., 2016. Addressing knowledge gaps in reptile conservation. Biol. Conserv. 204A, 1-5.

Tingley, R., Macdonald, S.L., Mitchell, N.J., Woinarski, J.C.Z., Meiri, S., Bowles, P., Cox, N.A., Shea, G.M., Böhm, M., Chanson, J., Tognelli, M., Harris, J., Walke, C., Harrison, N., Victor, S., Woods, C., Amey, A.P., Bamford, M., Catt, G., Clemann, N., Couper, P.J., Cogger, H., Cowan, M., Craig, M., Dickman, C.R., Doughty, P., Ellis, R., Fenner, A., Ford, S., Gaikhorst, G., Gillespie, G.R., Greenlees, M.J., Hobson, R., Hoskin, C.J., How, R., Hutchinson, M.N., Lloyd, R., McDonald, P., Melville, J., Michael, D.R., Moritz, C., Oliver, P.M., Peterson, G., Robertson, P., Sanderson, C., Somaweera, R., Teale, R., Valentine, L., Vanderduys, E., Venz, M., Wapstra, E., Wilson, S., Chapple, D.G., 2019. Geographic and taxonomic patterns of extinction risk in Australian squamates. Biol. Conserv. 238, 108203. https://doi.org/10.1016/j. biocon.2019.108203.

Tolley, K.A., Alexander, G.J., Branch, W.R., Bowles, P., Maritz, B., 2016. Conservation status and threats for African reptiles. Biol. Conserv. 204, 63-71.

Tolley, K.A., Weeber, J., Maritz, B., Verburgt, L., Bates, M.F., Conradie, W., Hofmeyr, M. D., Turner, A.A., da Silva, J.M., Alexander, G.J., 2019. No safe haven: protection levels show imperilled South African reptiles not sufficiently safe-guarded despite low average extinction risk. Biol. Conserv. 233, 61-72.

Uetz, P., Freed, P., Hošek, J. (Eds.), 2020. The Reptile Database (http://www.reptiledatabase.org, accessed 16th June 2020).

UNEP-WCMC, 2020. Protected Planet: The World Database on Protected Areas (WDPA). UNEP-WCMC and IUCN, Cambridge, UK. Available at: www.protectedplanet.net.

While, G.M., Gardner, M.G., Chapple, D.G., Whiting, M.J., 2019. Stable social grouping in lizards. Chapter 10. In: Bels, V.L., Russell, A.P. (Eds.), Behavior of Lizards: Evolutionary and Mechanistic Perspectives. CRC Press, Boca Raton, Florida, pp. 321-339.

Woinarski, J.C.Z., 2018. The extent and adequacy of monitoring for Australian threatened reptile species. In: Legge, S., Lindenmayer, D.B., Robinson, N.M., Scheele, B.C., Southwell, D.M., Wintle, B.A. (Eds.), Monitoring Threatened Species and Ecological Communities. CSIRO Publishing, Clayton, pp. 69-84.

Woinarski, J.C.Z., Murphy, B.P., Palmer, B.R., Legge, C.S.M., Dickman, C.R., Doherty, T. S., Edwards, G., Nankivell, A., Read, J.L., Stokeld, D., 2018. How many reptiles are killed by cats in Australia? Wildl. Res. 45, 247-266. 